\title{
Changing Trend of Dermatophyte Infections: A Five Year Study
}

\author{
Sunita Gajbhiye ${ }^{1 *}$, Nirmal Channe ${ }^{2}$, Sunanda Shrikhande ${ }^{3}$ \\ ${ }^{1}$ Associate Professor, Department of Microbiology, Government Medical College, Nagpur, Maharashtra, India \\ ${ }^{2}$ Assistant Professor, Department of Microbiology, Government Medical College, Nagpur, Maharashtra, India \\ ${ }^{3}$ Professor and Head, Department of Microbiology, Government Medical College, Nagpur, Maharashtra, India
}

\begin{abstract}
*Address for Correspondence: Dr. Sunita Gajbhiye, Associate Professor, Department of Microbiology, Government Medical College, Nagpur, Maharashtra, India

E-mail: sunitarajgaj@yahoo.com
\end{abstract}

Received: 27 Sep 2020/ Revised: 07 Nov 2020/ Accepted: 09 Feb 2021

\begin{abstract}
Background- Dermatophytosis is a common infection affecting humans globally. According to WHO, the prevalence rate of superficial mycotic infections worldwide is $20-25 \%$. The fungal infections of the skin and its appendages are more common in tropical countries like India, due to environmental factors like heat and humidity. In the recent past, there has been an increase in dermatophytic infections, which are caused by non-dermatophytic species of fungi. This study was undertaken to note the changing trend of dermatophytic infection for five years.

Methods- A total of 459 skin, hair and nail samples from clinically diagnosed cases of dermatophytoses attending Dermatology clinics were included in the study. Out of 459 samples, 116 (25.27\%) fungi were isolated, which included dermatophytic and nondermatophytic fungi.

Results- Amongst dermatophytes, the most common isolate was Trichophyton mentagrophytes (28.57\%) followed by Trichophyton rubrum (21.42\%) and Epidermophyton floccossum (21.42\%). The most common non-dermatophyte isolated was Aspergillus species (50.93\%) followed by Candida (15.68\%) and Fusarium (9.80\%).

Conclusion - In our study, non-dermatophytic isolates outnumbered dermatophytes and this reflects the changing trend of dermatophytic infections with a high isolation rate of non-dermatophytic fungi.
\end{abstract}

Key-words: Changing trend, Dermatophytosis, Dermatophytes, Non dermatophytes, Superficial mycotic infections

\section{INTRODUCTION}

Dermatophytes are a group of closely related fungi that tend to invade keratinized tissue, skin, hair and nails commonly referred to as ringworm ${ }^{[1]}$. The isolation of these agents from clinical specimens may pose a challenge to the clinicians unless there is proper identification of the organisms. Successful treatment of these infections requires a high index of clinical suspicion and knowledge of etiological agents ${ }^{[2]}$. The etiological agents of dermatophytoses are classified as Trichophyton, Epidermophyton and Microsporum and they are differentiated based on conidia formation ${ }^{[3]}$.

\section{How to cite this article}

Gajbhiye S, Channe N, Shrikhande S. Changing Trend of Dermatophyte Infections: A Five Year Study. SSR Inst. Int. J. Life Sci., 2021; 7(2): 2788-2793.

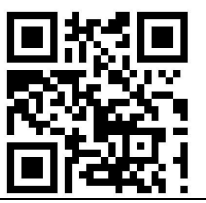

According to $\mathrm{WHO}$, the prevalence rate of superficial mycotic infections worldwide is $20-25 \%{ }^{[1]}$.

The fungal infections of the skin and its appendages are more common in tropical countries like India due to environmental factors like heat and humidity [4]. Although it does not cause mortality, it causes high morbidity and worsens the quality of patients' life ${ }^{[4]}$. The prevalence of dermatophytic infections with different species of dermatophytes varies with geographical locations and conditions. In the recent past, there has been an increase in dermatophytic infections which are caused by non-dermatophytic species of fungi. In addition to the accepted pathogens, there are significant numbers of non-dermatophytic fungi, which have been implicated in superficial mycoses ${ }^{[5,6]}$.

Dermatophytic and non-dermatophytic fungi implicated as a cause of dermatophytoses have been recorded all over the world but with variation in distribution, incidence, epidemiology, clinical manifestations and 
target hosts from one location to another ${ }^{[6]}$. Though several reports on dermatophyte infection are available from different parts of the country, there are only a few reports on non-dermatophytic fungi ${ }^{[1]}$.

The present study was undertaken to study the fungal etiology of dermatophytic infections in patients attending Dermatology clinics and to study the rising trend of non-dermatophytic fungi causing dermatophytosis over five years.

\section{MATERIALS AND METHODS}

The present study was conducted in the Department of Microbiology, Government Medical College, Nagpur from January 2015 to November 2019. A total of 459 skins, hair and nail samples from clinically diagnosed cases of dermatophytoses attending Dermatology clinics were included in the study.

The skin, hair and nail samples were processed as per standard recommended procedures. The samples were collected in sterile petri dishes and direct microscopy using $10-20 \% \mathrm{KOH}$ was done and was screened for fungal hyphae, spores or yeast cells. They were then inoculated on two sets of Sabouraud's Dextrose Agar containing Chloramphenicol and Cycloheximide and incubated at $25^{\circ} \mathrm{C}$ and $37^{\circ} \mathrm{C}$. The cultures were examined once a week and were declared negative if no growth was obtained till 4 to 6 weeks. The isolates were further identified by studying the culture characteristics, pigment production and microscopic examination using Lactophenol Cotton Blue mount and slide culture were done wherever necessary for identification of species ${ }^{[8]}$.

\section{RESULTS}

A total of 459 samples of skin, hair and nail were collected during the study period. The most common sample collected was of nail followed by skin and hair (Table 1).

Table 1: Specimen-wise distribution

\begin{tabular}{ccccc}
\hline Years & Nail & Skin & Hair & Total \\
\hline 2015 & 40 & 5 & 0 & 45 \\
2016 & 84 & 2 & 0 & 86 \\
2017 & 92 & 1 & 1 & 94 \\
2018 & 100 & 2 & 0 & 102 \\
2019 & 131 & 1 & 0 & 132 \\
Total & 447 & 11 & 1 & 459 \\
\hline
\end{tabular}

Out of 459 samples, 116 (25.27\%) fungi were isolated. It was observed that there is an increase in sample size over the years (Table 2 ).

Table 2: Fungi isolation rate from samples received

\begin{tabular}{ccc}
\hline Years & No. of samples & No. of fungi \\
\hline 2015 & 45 & 12 \\
2016 & 86 & 18 \\
2017 & 94 & 24 \\
2018 & 102 & 28 \\
2019 & 132 & 34 \\
Total & 459 & $116(25.27 \%)$ \\
\hline
\end{tabular}

Table 3: Fungi isolation rate from dermatophytosis in various places

\begin{tabular}{|c|c|c|c|}
\hline Study & Years & Place & $\begin{array}{c}\text { Percentage } \\
(\%)\end{array}$ \\
\hline $\begin{array}{c}\text { Teklebirhan et al. } \\
{[11]}\end{array}$ & 2015 & Ethiopia & 73.40 \\
\hline Naglot et al. ${ }^{[12]}$ & 2015 & Assam & 59.66 \\
\hline Kannan et al. ${ }^{[13]}$ & 2016 & Tamilnadu & 66.30 \\
\hline Hazarika et al. ${ }^{[7]}$ & 2019 & Assam & 47.69 \\
\hline Angadi et al. ${ }^{[15]}$ & 2019 & Pune & 73.57 \\
\hline Present study & 2019 & Nagpur & 25.27 \\
\hline
\end{tabular}

In our study, out of 116 fungi isolated 14 (12.06\%) were dermatophytes and 102 (87.93\%) were non dermatophytes (Table 4). 
Table 4: Dermatophytic and Non Dermatophytic fungi isolated from dermatophytosis cases

\begin{tabular}{cccc}
\hline Years & No. of fungi isolated & Dermatophytes & Non-dermatophytes \\
\hline 2015 & 12 & 4 & 8 \\
2016 & 18 & 3 & 15 \\
2017 & 24 & 3 & 21 \\
2018 & 28 & 2 & 26 \\
2019 & 34 & 2 & 32 \\
Total & 116 & $14(12.06 \%)$ & $102(87.93 \%)$ \\
\hline
\end{tabular}

Table 5: Dermatophytic and Non-dermatophytic fungi isolated from dermatophytosis cases in different studies

\begin{tabular}{cccc}
\hline Authors & Years & Dermatophytes (\%) & Non-dermatophytes (\%) \\
\hline Teklebirhan et al. $^{[11]}$ & 2015 & 58 & 42 \\
Bitew $^{[14]}$ & 2018 & 54.43 & 47.56 \\
Hazarika et al. $^{[7]}$ & 2019 & 43.54 & 56.46 \\
Present study & 2019 & 12.06 & 87.93 \\
\hline
\end{tabular}

During the study period (2015-2019), out of 116 fungi isolated, 14 (12.06\%) were dermatophytes. The year-wise identification of dermatophytes is shown in Table 6.

Table 6: Year wise Identification of Dermatophytes $(n=14)$

\begin{tabular}{lcccccc}
\hline \multirow{2}{*}{ Dermatophytes } & \multicolumn{7}{c}{ No. of isolates } \\
\cline { 2 - 6 } & $\mathbf{2 0 1 5}$ & $\mathbf{2 0 1 6}$ & $\mathbf{2 0 1 7}$ & $\mathbf{2 0 1 8}$ & $\mathbf{2 0 1 9}$ & Total \\
\hline $\begin{array}{l}\text { T. mentagrophytes } \\
\text { T. rubrum }\end{array}$ & 2 & 2 & - & - & - & 4 \\
T. violaceum & - & 1 & - & 1 & 1 & 3 \\
T. tonsurans & 2 & - & 1 & - & - & 3 \\
E. flocossum & - & - & - & 1 & - & 1 \\
Total & - & - & 2 & - & 1 & 3 \\
\hline
\end{tabular}

In this present study, the commonest isolate among dermatophytes was $T$. vmentagrophytes (28.57\%). Some studies have shown $T$. mentagrophytes as the common isolate while other workers have found $T$. rubrum as the common isolate (Table 7). 
Table 7: Dermatophytic fungi isolated from Dermatophytosis cases in different studies

\begin{tabular}{cccccc}
\hline Authors & $\begin{array}{c}\text { T. } \\
\text { mentagrophytes (\%) }\end{array}$ & $\begin{array}{c}\text { T. } \\
\text { rubrum (\%) }\end{array}$ & $\begin{array}{c}\text { T. } \\
\text { tonsurans (\%) }\end{array}$ & $\begin{array}{c}\text { T. } \\
\text { violaceum (\%) }\end{array}$ & $\begin{array}{c}\text { E. flocossum } \\
\text { (\%) }\end{array}$ \\
\hline Sharma et al. ${ }^{[5]}$ & 40.33 & 6.6 & - & - & - \\
Uma et al. ${ }^{[15]}$ & 30.58 & 37.64 & - & - & - \\
$\begin{array}{c}\text { Rathod et al. } \\
{[16]}\end{array}$ & 28.57 & 51.19 & 7.15 & 3.57 & \\
$\begin{array}{c}\text { Kannan et al. }{ }^{[9]} \\
\text { Gunasekaran } \\
\text { et al. }{ }^{[10]}\end{array}$ & 16.7 & 70.83 & - & - & 3.33 \\
Present study & 30.69 & 39.2 & - & 3.2 & \\
\hline
\end{tabular}

A total of 102 (87.93\%) non-dermatophytes were isolated in our study. The species wise distribution of nondermatophytes is shown in Table 8.

Table 8: Species wise distribution of Non-dermatophytes ( $n=102)$

\begin{tabular}{cccc}
\hline Non-dermatophytes & No. of isolates & Penicillium sp. & 5 \\
Aspergillus sp. & 52 & P. marneffi & 5 \\
Aspergillus niger & 32 & Rhizopus sp. & 6 \\
Aspergillus fumigatus & 12 & R. arrihizus & 6 \\
Aspergillus flavus & 4 & Mucor sp. & 6 \\
Aspergillus nidulans & 2 & M. racemosus & 6 \\
Aspergillus glaucus & 1 & Curvularia sp. & 2 \\
Aspergillus versicolor & 1 & C. geniculata & 2 \\
Candida sp. & 16 & Alternaria sp. & 1 \\
Candida albicans & 10 & A. alternata & 1 \\
Candida tropicalis & 3 & Cladosporium sp. & 2 \\
Candida krusei & 2 & C. bantiana & 2 \\
Candida glabrata & 1 & Exophiala sp. & 1 \\
Fusarium sp. & 10 & E. werneckii & 1 \\
Fusarium solani & 8 & Fonsaeca pedrosii & 1 \\
Fusarium oxysporum & 2 & Total & 102 \\
\cline { 3 - 4 } & & & \\
\hline
\end{tabular}


The most common non-dermatophyte isolated in our study was Aspergillus sp. (50.98\%) followed by Candida spp. (15.68\%) and Fusarium sp. (9.8\%). In a study by Sharma et al. ${ }^{[5]}$, the most common NDM isolated was Aspergillus sp. (64.51\%). Kannan et al. ${ }^{[8]}$ found a higher isolation rate of Candida (58.6\%). The bar diagram is shown below shows increasing sample size over the years and increased isolation of non-dermatophytes (Fig. 1).

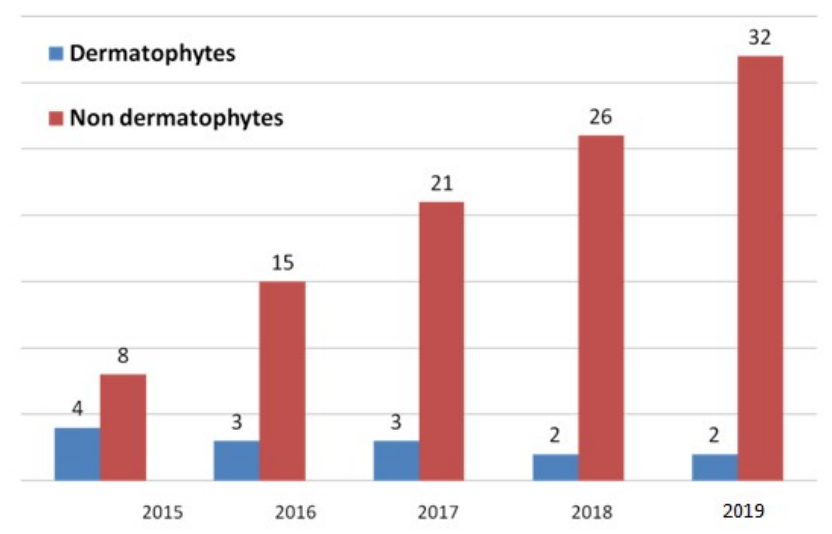

Fig. 1: Dermatophytes v/s Non-dermatophytes

Dermatophytosis caused by non-dermatophytic fungi is not uncommon now. The myth that non-dermatophytes are to be considered as laboratory contaminants does not hold always. To consider non-dermatophytic fungi as a causative agent, it should be positive indirect microscopy and re-isolation.

\section{DISCUSSION}

A total of 459 samples of skin, hair and nail were collected during a five year study period. The most common sample collected was of nail infection followed by skin and hair. However, Kannan et al. ${ }^{[9]}$ and Gunasekaran et al. ${ }^{[10]}$ found skin samples to be the common sample collected. Out of 459 samples, 116 (25.27\%) fungi were isolated in our study and there was an increase in sample size over the years. In our study in the year 2016, the isolation rate was $20.9 \%$, which gradually increased to $25.75 \%$ in 2019 . Other workers have shown different isolation rates of dermatophytosis from various places. Teklebirhan et al. ${ }^{[11]}$ in the year 2015 in Ethiopia found an isolation rate of $73.40 \%$. In a study by Kannan et al. ${ }^{[9]}$ in 2016 in Tamil Nadu, they found an isolation rate of $66.30 \%$. However, Angadi et al. ${ }^{[13]}$ in 2019 in Pune found an isolation rate of $23.57 \%$.
Further, in our study, the isolation rate of dermatophytes versus non-dermatophytes had an increasing trend over the years from 2015 to 2019 as shown in Table 4. Similarly, other workers have shown an increasing isolation rate of non-dermatophytes from various regions as shown in Table 5. Hazarika et al. ${ }^{[7]}$, in 2019, isolated $43.54 \%$ dermatophytes and $56.46 \%$ nondermatophytes. In our study, we isolated $12.06 \%$ dermatophytes and $87.93 \%$ non-dermatophytes, which clearly show an increasing trend of isolation of nondermatophytic isolates from cases of dermatophytosis. In the present study, the most common isolate among dermatophytes was $T$. mentagrophytes (28.57\%) followed by $T$. rubrum (28.42\%). Sharma et al. ${ }^{[5]}$ isolated $40.33 \%$ of $T$. mentagrophytes and $6.6 \%$ of $T$. rubrum. However, Gunasekaran et al. ${ }^{[10]}$ isolated $30.69 \%$ of $T$. mentagrophytes and $39.2 \%$ of $T$. rubrum as shown in Table 7.

The most common non-dermatophyte isolated in our study was Aspergillus species (50.98\%) followed by Candida (15.68\%) and other non-dermatophytic moulds isolated were $23.52 \%$. This study done by Sharma et al. ${ }^{[5]}$, the most common non-dermatophytic mould isolated was Aspergillus species (64.51\%) and Kannan et al. ${ }^{[9]}$ found higher isolation rate of Candida species (58.6\%) among the non-dermatophytes.

\section{CONCLUSIONS}

In our study, nail infections were commonly found. Among dermatophytes, Trichophyton species were more common. Among non dermatophytes, Aspergillus species was the most common isolate. A rising trend of non-dermatophytic isolates from cases of dermatophytosis is seen in the study. Dermatophytosis caused by non-dermatophytic fungi is not uncommon now.

The myth that non-dermatophytes are to be considered as laboratory contaminants does not hold always. Accurate diagnosis is important for successful treatment, which requires laboratory confirmation.

\section{CONTRIBUTION OF AUTHORS}

Research concept- Sunita Gajbhiye, Nirmal Channe, Sunanda Shrikhande

Research design- Sunita Gajbhiye, Nirmal Channe

Supervision- Dr. Sunita Gajbhiye, Dr. Nirmal Channe, Dr. Sunanda Shrikhande

Materials- Sunita Gajbhiye, Nirmal Channe 
Data collection- Sunita Gajbhiye, Nirmal Channe

Data analysis and interpretation- Sunita Gajbhiye, Nirmal Channe

Literature search- Sunita Gajbhiye, Nirmal Channe, Sunanda Shrikhande

Writing article- Sunita Gajbhiye, Nirmal Channe

Critical review- Sunita Gajbhiye, Nirmal Channe, Sunanda Shrikhande

Article editing- Sunita Gajbhiye, Nirmal Channe, Sunanda Shrikhande

Final approval- Sunita Gajbhiye, Nirmal Channe, Sunanda Shrikhande

\section{REFERENCES}

[1] Jagdish C. Textbook of Medical Mycology. $2^{\text {th }}$ ed., New Delhi, India; Mehta Publishers: 2018; pp. 16284.

[2] Priyanka K, Sharmila S, Sonal C, Ravindra K. Mycological profile of fungal infections from various clinical samples in a tertiary care hospital. Indian J Res., 2019; 8: 8.

[3] Larone DH. Medically important fungi; A Guide to identification. $4^{\text {th }}$ ed., Washington DC; American society for Microbiology press: 2002; pp. 231.

[4] Cheesbrough M. District Laboratory Practice in Tropical Countries. $2^{\text {nd }}$ ed., Cambridge University Press: 2006; pp. 234.

[5] Sharma R, Adhikari L, Sharma RL. Recurrent Dermatophytosis: $A$ rising Problem in Sikkim, $A$ Himalayan state of India. Indian J Pathol Microbiol., 2017; 60: 541-45.

[6] Singh SM, Barde AK. Non dermatophytes as emerging oppourtunistic causal agents of superficial mycoses at Balaghat M.P. Indian J Dermatol Venereol Leprol, 1990; 56: 289-92.

[7] Deebeeka H, Nazneen J, Ajanta S. Changing trend of superficial mycoses with increasing nondermatophyte mold infection: Actinicomycological study at a tertiary center in Assam. Indian J Dermatol., 2019; 64(4): 261-65.
[8] Milne LJR. Standard Microbiological techniques, Fungi, In J.G.Collee, AG Fraser, BP Marmion, A. Simmons Editors Mackie \& McCartney Practical Medical Microbiology. $14^{\text {th }}$ ed., New York; Churchill Livingstone. Longman, Singapore Pubblisher: 1996; pp. 695-720.

[9] Kannan P, Janaki C, Selvi GS. Prevalence of Dermatophytes and other fungal agents isolated from clinical samples. Indian J Med Microbiol., 2006; 24: 212-15.

[10]Gunasekaran P. Prevalence of Dermatophytosis in patients in a tertiary care center in and around Cuddalore district. IAIM, 2017; 4 (8): 91-95.

[11]Teklebirhan G, Adane B. Profile of Dermatophyte and Non Dermatophyte fungi in patients suspected of Dermatophytosis. Am J Life Sci., 2015; 3(5): 352-57.

[12]Naglot A, Shrimali D, Nath BK, Gogoi HK, Vijay V, et al. Recent trends of Dermatophytosis in North East India (Assam) and interpretation with published studies. Int J Curr Microbiol App Sci., 2015; 4(11): 111-20.

[13]Angadi K, Misra R, Das NK, Kapoor S, Mirza S. Study of etiological agents of dermatophytosis in patients attending dermatology clinics of a sub urban tertiary care centre in western Maharashtra India. Int J Curr Microbiol App Sci., 2019; 8(6): 493-501.

[14]Adane B. Dermatophytosis: Prevalence of Dermatophytes and non dermatophyte fungi from patients attending Arsho Advanced Medical Laboratory, Addis Ababa, Ethiopia. Hindawi Dermatol Res Practice, 2018; pp. 1-6.

[15] Uma P, Ramesh BM, Padmaja Y, Susmitha S. A study of Prevalance of Dermatophytosis in and around Guntur District, Andhra Pradesh, South India. Int J Curr Microbiol App Sci., 2016; 9(5): 702-17.

[16]Rathod PG, Shaikh NK, Ingole KV, Mugadha SG. Prevalance of Dermatophytoses in a tertiary care center of Solapur, Maharashtra. J Krishna Institute of Med Sci Univ., 2016; 5(3): 26-34. 